Personalidade Acadêmica Homenageada:

Florisbal de Souza Del'Olmo (Professor Convidado - UNICURITIBA)

\title{
LEI ANTICORRUPÇÃO: NECESSIDADE E APLICABILIDADE
}

\author{
ANTICORRUPTION LAW: NEED AND APPLICABILITY
}

\section{ANDREIA AZEVEDO DE LIMA WADA}

Advogada. Mestre em Derecho de Daños pela UDG - Universitat de Girona/Espanha.Mestranda em Direito Empresarial e Cidadania do Unicuritiba. Médica Veterinária pela PUC-PR. Especialista em Gestão da Qualidade e Vigilância Sanitária de Produtos de origem animal. Especialista em Clínica Médica e Cirúrgica de Pequenos Animais.

\section{RESUMO}

O presente artigo tem como escopo a análise da Lei Anticorrupção, busca-se verificar a sua necessidade e aplicabilidade, bem como verificar algumas criticas com relação aos dispositivos constante na lei. Resulta necessário descrever brevemente o cenário de surgimento desta lei, e verificar a sua necessidade de aplicação, descrever algumas formas de prevenção da corrupção com a utilização de algumas práticas como a implantação de métodos como compliance, e dispor sobre algumas críticas que esta Lei sofreu. Utilizando-se a metodologia para o desenvolvimento o dedutivo, bibliográfico. A importância do estudo deriva do fato de que a prática de ilícitos por pessoa jurídica traz consigo diversas negativas de crescimento e desenvolvimento para uma nação, e para isso o combate a esta prática precisa ser legalmente reconhecido e aplicado, com isso a Lei Anticorrupção tem um papel fundamental para buscar a responsabilidade da pessoa jurídica e a tipologia dos atos ilícitos, para que se possam aplicar as devida sanções, almejando o comportamento ético e cumprimento dos seus deveres jurídicos. 
Personalidade Acadêmica Homenageada:

Florisbal de Souza Del'Olmo (Professor Convidado - UNICURITIBA)

PALAVRAS-CHAVE: Lei Anticorrupção; Compliance; Corrupção nas Empresas.

\section{ABSTRACT}

The purpose of this article is to analyze the Anti-Corruption Law, to verify its necessity and applicability, as well as to verify some critics regarding the devices contained in the law. It is necessary to briefly describe the scenario of the emergence of this law, to verify its need for application, to describe some forms of prevention of corruption with the use of some practices such as the implementation of methods such as compliance, and to provide some criticisms that this Law suffered. Using the methodology for the development of the deductive, bibliographic. The importance of the study stems from the fact that the practice of illicit by a legal person brings with it several negatives of growth and development for a nation, and for that the fight against this practice needs to be legally recognized and applied, with that the AntiCorruption Law has a a fundamental role for seeking the responsibility of the legal entity and the typology of illegal acts, so that appropriate sanctions can be applied, aiming at ethical behavior and compliance with their legal duties.

KEYWORDS: Anti-Corruption Law; Compliance; Corruption in Companies.

\section{INTRODUÇÃO}

O Brasil vive um momento em que a preocupação com a corrupção no sentido de persecução e investigação de crimes contra o patrimônio público e crimes econômicos, devido ao alto índice de corrupção que se instalou e se disseminou ao longo de décadas, perpassando vários governos e regimes de governo adotado, está cada vez mais sendo motivo para a criação de novas medidas anticorrupção, e leis que inibam esta prática. 
Personalidade Acadêmica Homenageada:

Florisbal de Souza Del'Olmo (Professor Convidado - UNICURITIBA)

A impressão emanada com relação à corrupção é de que esta permeia largamente as atividades realizadas entre empresas e poder público, segundo o que esta sendo indicado em diversas pesquisas, e o que podemos também observar com o desenvolvimento das investigações iniciadas com a operação lava jato e outras operações anteriores a ela, e as decisões judiciais que condenaram muitas empresas e pessoas envolvidas na corrupção.

Com o desenvolvimento da tecnologia e o crescente aumento das fronteiras negociais, crescem também as práticas ilícitas, e os atos de corrupção, sendo assim, com esta globalização econômica, as exigências mundiais em coibir estas condutas ilícitas por pessoas jurídicas, trouxe a necessidade de se regulamentar os mercados globais.

Em razão disso, segundo Cunha e Souza (2017, p. 16)

\begin{abstract}
A globalização da economia e das relações sociais intensificadas no século passado, as implicações transnacionais da corrupção, e a constatação de que as leis internas tradicionais quase sempre fracassam como resposta às práticas corruptas que ocorrem no mudo, obrigou o tema corrupção a ser prioridade na agenda de discussão da comunidade internacional, demandando o desenvolvimento de mecanismos de prevenção e punição dos atos lesivos à administração pública.
\end{abstract}

Ademais, as práticas de corrupção tendem a transformar as relações negociais contaminadas por desconfianças que geraram prejuízos ao desenvolvimento das nações.

Neste sentido o Brasil promulgou a Lei no 12.846/2013, conhecida como Lei Anticorrupção, a qual veio para preencher uma lacuna normativa e promover o endurecimento no combate à corrupção da pessoa jurídica. Surge assim à questão, objeto do presente estudo, qual a necessidade e aplicabilidade da Lei Anticorrupção?

Com o propósito de obter resposta ao objetivo proposto, analisou-se a Lei no sentido de buscar compreender sua importância, bem como a necessidade de aplicação, utilizando-se a metodologia para o desenvolvimento do artigo, que 


\section{Personalidade Acadêmica Homenageada:}

Florisbal de Souza Del'Olmo (Professor Convidado - UNICURITIBA)

observa uma lógica indutiva, utiliza meio de pesquisa bibliográfica, mediante explicações embasadas em trabalhos publicados em livros, artigos e lei vigente.

A pesquisa mostra-se relevante, pois a corrupção por ser uma prática ilícita, traz consigo diversas negativas de crescimento e desenvolvimento para uma nação, e para isso o combate a esta prática precisa ser legalmente reconhecido e aplicado, com isso a Lei Anticorrupção tem um papel fundamental para buscar a responsabilidade da pessoa jurídica e a tipologia dos atos ilícitos, para que se possam aplicar as devida sanções, almejando o comportamento ético e cumprimento dos seus deveres jurídicos.

No entanto, a Lei apresenta algumas criticas relevantes quanto algumas diretrizes e disposições de conteúdo de seu texto, o que foi abordado brevemente como um contraponto a sua necessidade e aplicabilidade.

\section{SURGIMENTO DA LEI E SUA NATUREZA JURÍDICA}

A corrupção não é uma prática nacional, mas sim mundialmente praticada, com a finalidade de minimizar e de sancionar os que dela obtém vantagens, houve um movimento internacional liderado pela Organização para Cooperação e Desenvolvimento Econômico - OCDE, juntamente com o Banco Mundial, com o propósito de promover o nivelamento de competitividade das empresas, e este também teve influência do Foreign Corrupt Practices Act (FCPA); o UK Bribery Act; a Convenção Interamericana contra a Corrupção da Organização dos Estados Americanos (OEA) e a Convenção sobre Combate à Corrupção de Funcionários Públicos Estrangeiros em Transações Comerciais Internacionais da Organização para Cooperação e Desenvolvimento Econômico (OCDE).

No Brasil o combate à corrupção criou forças a partir do ano de $1950 \mathrm{com}$ a Lei que regula o crime de responsabilidade, posteriormente a Lei de Ação Popular de 1965; a Lei de Ação Civil Pública em meados de 1985. A própria Constituição de 1988 trouxe sanções às práticas de improbidade administrativa. Já em 1992 surge a 
Personalidade Acadêmica Homenageada:

Florisbal de Souza Del'Olmo (Professor Convidado - UNICURITIBA)

Lei que traz cominações aos agentes públicos que enriquecem ilicitamente, e em 1993 adveio a Lei das Licitações e Contratos. Esta lei prevê responsabilização e aplicação de penalidades aquelas entidades que firmam Contratos de Gestão, Termo de Parceria, Convênios, acordos e ajustes, que por meio destes praticam atos de improbidade administrativa.

A Lei Anticorrupção surge pelo fato do Brasil fazer parte da Convenção das Nações Unidas contra Corrupção, e com este compromisso internacional, o qual foi ratificou por meio do Decreto ํㅜ 5.687 de 2006, e em meio a um clamor popular, e no cumprimento das obrigações assumidas nessa Convenção, alterou o Código Penal por meio da Lei no 10.467/2002, dando ensejo aos artigos 337-B e 337-C, bem como se obrigou a criar a Lei no 12.846 de 2013.

Esta Lei tem natureza jurídica punitiva, ou seja, faz parte do Direito Administrativo Sancionador, Penal e Cível.

Neste passo, e apoiado na Constituição Brasileira, Osório entende que:

Do exposto, o que se percebe é que o Direito Penal e o Direito Administrativo Sancionador, se bem que não se valham invariavelmente das mesmas técnicas, nem encontrem os mesmos regimes jurídicos, acabam adentrando núcleos dos direitos fundamentais dos acusados em geral, na perspectiva da submissão às chamadas cláusulas do devido processo legal e do Estado de Direito. O Direito Punitivo, assim encontra um núcleo básico na Constituição Federal, núcleo normativo do qual emanam direitos constitucionais de conteúdos variáveis, embora com pontos mínimos em comum e aqui talvez resida a confusão conceitual em torno ao debate sobre Direito Público Punitivo. E é precisamente aqui que se deve compreender a unidade do Direito Sancionador: há cláusulas constitucionais que dominam tanto o Direito Penal, quanto o Direito Administrativo Punitivo. Tais cláusulas, se bem que veiculem conteúdos distintos, também veiculam conteúdos mínimos obrigatórios, onde repousa a ideia de unidade mínima a vincular garantias constitucionais básicas aos acusados em geral. (OSÓRIO, 2015, p. 144).

De outro norte Zaffaroni e Pierangeli entendem que esta função punitiva do Direito Administrativo Sancionador deve respeitar as garantias que vigoram para a legislação penal, como descrevem: 
Personalidade Acadêmica Homenageada:

Florisbal de Souza Del'Olmo (Professor Convidado - UNICURITIBA)

Temos afirmado que o direito penal é o único cuja coerção procura a prevenção especial, ao passo que o resto da ordem jurídica procura a reparação (que inclui a reposição, quando é possível). Enquanto o resto da ordem jurídica provê a segurança jurídica mediante a sanção reparadora (salvo aquelas normas cujas consequências jurídicas não são propriamente sanções, como as medidas tutelares ou assistenciais), e a totalidade das sanções reparadoras configura a função de prevenção especial, posto que com a geral não se satisfaça suficientemente a segurança jurídica. $O$ direito penal administrativo se caracteriza por prover a segurança jurídica por ambas às vias. Daí que dita legislação, por participar parcialmente da função preventiva especial, deve respeitar as garantias que vigoram para a legislação penal. Tais garantias devem ser respeitadas por toda lei que participe - ainda que parcialmente - da natureza penal e mesmo que não seja, propriamente falando, uma lei penal. (ZAFFARONI; PIERANGELI, 2008, p. 133).

De acordo com o entendimento de Cunha e Souza (2017, p. 19):

A Lei 12.846/13 não tem natureza penal. E nem poderia deixar de ser diferente porque no Brasil, só é admitida a responsabilidade penal da pessoa jurídica nos crimes ambientais. Verifica-se na Lei muitos conceitos jurídicos típicos do direito administrativo, do direito empresarial e do direito civil. A interpretação de características de diferentes ramos do direito na lei é bem-vinda, embora possa causar alguma dificuldade interpretativa.

Segundo o pensamento dos mesmos autores (idem, ibidem) "a percepção nacional é de que a corrupção permeia as atividades entre empresas e poder público conforme indicam inúmeras pesquisas atuais. Embora ainda haja uma cumplicidade da população com atos de desonestidade envolvendo a coisa pública [...]". Neste sentido, a Lei veio para responsabilizar aquele que por ato ilícito cometerem corrupção, seja um particular ou um agente público, estabelecendo um conjunto de normas que previnem esses atos, evidenciando a ética como norte. E é sobre a sua importância e aplicabilidade tratou o item seguinte.

\section{IMPORTANCIA E APLICABILIDADE DA LEI}

A Lei anticorrupção foi criada para suprir uma lacuna legislativa no ordenamento jurídico brasileiro no que tange a responsabilização da pessoa jurídica 
Personalidade Acadêmica Homenageada:

Florisbal de Souza Del'Olmo (Professor Convidado - UNICURITIBA)

pelas práticas de atos ilícitos contra a administração pública especialmente por praticas de corrupção, devido a compromisso anteriormente assumido em âmbito internacional.

No plano da moral os atos de corrupção decorrentes da busca de lucro fácil sempre foram considerados absolutamente reprováveis. Neste quadro, o risco de cometimento de fraudes é fruto da agressividade do mercado competitivo que leva a uma demanda por vendas, por lucros e resultados. (CUNHA; SOUZA, 2017, p. 24).

Inicialmente, segundo seu preâmbulo, a lei dispõe sobre a responsabilização administrativa e civil de pessoas jurídicas pela prática de atos contra a administração pública, nacional ou estrangeira. E é destinada, de acordo com o parágrafo único do artigo primeiro:

Aplica-se o disposto nesta Lei às sociedades empresárias e às sociedades simples, personificadas ou não, independentemente da forma de organização ou modelo societário adotado, bem como a quaisquer fundações, associações de entidades ou pessoas, ou sociedades estrangeiras, que tenham sede, filial ou representação no território brasileiro, constituídas de fato ou de direito, ainda que temporariamente. (BRASIL, 2013, s/p).

Importa destacar que a responsabilização disposta na lei é objetiva em relação à pessoa jurídica, e subjetiva em relação aos dirigentes e administradores, sendo que uma não exclui a outra. E o disposto no artigo 5o, encontra-se o rol taxativo dos atos lesivos à administração pública e punível, sendo que esse rol não permite analogia. Segundo Hage Sobrinho $(2014$, p. 4) as sanções são voltadas para:

-Sanções que alcancem diretamente o agente corruptor pessoa jurídica; • Sanções que atinjam o patrimônio da empresa corruptora, possibilitando, inclusive, o ressarcimento dos cofres públicos; • Sanções aplicáveis também pela via administrativa, além daquelas acionáveis pela via judicial cível; • Responsabilização objetiva, independentemente de culpa ou dolo; • Sanções realmente eficazes (isto é, com real poder inibitório, preventivo, dissuasório); • Normativo não apenas repressivo, mas que atue, sobretudo, como poderoso instrumento de prevenção da corrupção, incentivando a integridade corporativa nas empresas (pelo sistema de atenuantes, que 


\section{Personalidade Acadêmica Homenageada:}

Florisbal de Souza Del'Olmo (Professor Convidado - UNICURITIBA)

valoriza sobretudo os bons programas de compliance); • Normas voltadas à facilitação e agilização da investigação, com a colaboração da empresa, via Acordo de Leniência; e • Regras aplicáveis também à corrupção transnacional.

Ou seja, os atos que atentarem contra o patrimônio público, nacional ou estrangeiro, bem como contra os princípios da Administração Pública ou que venha a lesar compromissos internacionais assumidos pelo Brasil, serão punidos com base nesta Lei.

Os contratos Administrativos realizados por meio de processo licitatórios foram valorados no sentido de dar importância a competitividade no procedimento, trazendo a punibilidade até mesmo a atos que venham a perturbar a realização do certame, com a finalidade de efetivar a competitividade. É o disposto no art. 5o, inciso IV e alíneas.

Marcio Pestana (2016, p. 52) entende que "as fraudes cometidas em relação aos contratos celebrados pela Administração Pública que sejam consequentes à realização do certame licitatório ou, mesmo, da sua não realização (contratações diretas), também serão consideradas condutas lesivas passiveis de sofrerem o apenamento preconizado pela Lei Anticorrupção".

Quanto à responsabilização objetiva da pessoa jurídica, de acordo com entendimento de Moreira Neto e Freitas (2014, s/p).

Tal dispositivo, acompanhando a tendência de objetivação da responsabilidade civil e administrativa no ordenamento jurídico nacional, prevê que as corporações poderão ser sancionadas por atos de corrupção praticados por seus prepostos, independentemente da comprovação de dolo ou culpa. Ou seja: para fins de responsabilização, bastará que seja comprovado $o$ ato de corrupção e o nexo de causalidade entre ele e conduta de qualquer representante das pessoas jurídicas envolvidas.

É o caso do disposto no art. $2^{\circ}$, que prevê que, "As pessoas jurídicas serão responsabilizadas objetivamente, nos âmbitos administrativo e civil, pelos atos lesivos previstos nesta Lei praticados em seu interesse ou benefício, exclusivo ou não" (BRASIL, 2013, s/p). Sendo assim, a responsabilização será efetiva quando o ato tenha produzido benefícios em favor da empresa ou em favor de terceiros. 
Personalidade Acadêmica Homenageada:

Florisbal de Souza Del'Olmo (Professor Convidado - UNICURITIBA)

Trata-se de sistema que simplifica a responsabilização por atos ilícitos, instituindo mecanismos que permitem um sujeito receber uma sanção pela conduta de um terceiro, independentemente de ter concorrido para tanto. Essa responsabilidade vicariante é prevista no artigo 932 do Código Civil. (CUNHA; SOUZA, 2017, p. 26).

Os artigos $6^{0}$ e $7^{0}$ preveem a sanção pecuniária e não pecuniária, bem como os parâmetros possíveis a serem considerados para a dosimetria.

Ademais, o art. 7º, VIII, especifica que será levada em conta na aplicação de sanções a adoção ou não, por parte da empresa, do Compliance, sendo a "existência de mecanismos e procedimentos internos de integridade, auditoria e incentivo à denúncia de irregularidades e a aplicação efetiva de códigos de ética e de conduta no âmbito da pessoa jurídica". (BRASIL, 2013, s/p)

Segundo entendimento de Marco Vinicio Petreluzzi e Rubens Naman Rizek Junior (2014, p. 54) "o bem jurídico tutelado pela Lei n. 12.846/2013 é o patrimônio público, seja ele nacional ou estrangeiro. De outra parte, a norma visa à proteção de bens imateriais, consubstanciados nos princípios que regem a administração publica, além da moralidade pública".

\begin{abstract}
A Lei Anticorrupção tem como primeiro fundamento de validade o direito fundamental à probidade administrativa que, por caracterizar-se como direito fundamental, sujeita-se à teoria da horizontalização dos direitos fundamentais. Deste modo irradia efeitos e tem projeção nas relações entre particulares, seja entre indivíduos que tem relação jurídica com o Estado, seja entre cidadãos usuários dos serviços estatais. Seu feixe irradiante estabelece, mesmo nas relações privadas, verdadeiro dever cívico de todos os cidadãos em combater os desmandos administrativos uma vez que a proteção a esse novo direito fundamental é incumbência e responsabilidade de todos. (CUNHA; SOUZA, 2017, p.23-24).
\end{abstract}

A responsabilização da pessoa jurídica trazida pela lei foi um grande avanço contra a impunibilidade, pois até então as sanções somente eram aplicadas aos agentes causadores do dano, porém foi ampliado podendo ser ambos responsabilizados, como se observa no artigo 1응 o qual cita expressamente a responsabilização objetiva administrativa e civil, por meio de processo administrativo 


\section{Personalidade Acadêmica Homenageada:}

Florisbal de Souza Del'Olmo (Professor Convidado - UNICURITIBA)

com observação do contraditório e ampla defesa, porém essa responsabilização não afasta a possibilidade de se buscar a esfera judicial, é o que prevê o artigo 18 da Lei.

A responsabilização da pessoa jurídica somente será descartada se ficar comprovado à ausência do nexo de causalidade, porém, de acordo com Cunha e Souza (2017, p. 31) "cumpre destacar que a pessoa jurídica é responsável pelo ato ilícito praticado em razão dos serviços por elas prestados, ainda que terminada a execução, pouco importando também que o ato lesivo não esteja dentro das funções do preposto. Basta que essas funções facilitem sua prática".

Moreira Neto e Freitas (2014, s/p) referem que a Lei Anticorrupção, além de buscar a concretude do princípio da moralidade, é "um diploma normativo que tem por objeto justamente a repressão de condutas de agentes privados que fomentem a prática de imoralidades por servidores do Estado, estabelecendo sanções e instrumentos normativos para a sua persecução".

Outra inovação foi o incentivo a cooperação das empresas com os órgão e controle, por meio do acordo de leniência, trazendo benefícios aos cooperadores podendo isentá-la de certas sanções, bem como reduzir o valor de uma multa eventualmente aplicável, sendo caracterizada por alguns juristas como sendo uma espécie de delação premiada. "Deve ser alertado, ainda, que o ajuste de leniência só é cabível para a pessoa jurídica que seja a primeira a se manifestar sobre seu interesse em cooperar para a apuração do ato ilícito" (CUNHA; SOUZA, 2017. p. 75).

A Lei Anticorrupção foi aprovada com a intenção de trazer benefícios ao Estado a fim de alavancar o crescimento por intermédio da probidade, da ética bem como da moralidade na administração dos recursos públicos e da prática de mercado, e com isso trazer ganhos na luta do combate à corrupção no Brasil. Porém há que se ter cautela quanto às criticas aos dispositivos nela constantes, pois ainda sua aplicação é recente, por conseguinte seus efeitos serão notados ao longo de sua constante aplicação.

Como entendem Cunha e Souza (2017, p. 21) "seja como for, a Lei Anticorrupção é espécie de direito sancionador que adota técnicas de controle social 


\title{
Personalidade Acadêmica Homenageada:
}

Florisbal de Souza Del'Olmo (Professor Convidado - UNICURITIBA)

de desencorajamento de comportamento reprovável, através das sanções de caráter simultaneamente preventivo e dissuasivo".

Outra forma de atuação da Lei é com relação ao fundamento de validade a função social da empresa, o que tem sua raiz na função social da propriedade, e esta prevista no art. 170, II da CRFB/1988, representa um importante princípio que valoriza a coletividade, bem como associado à eticidade e a sociabilidade, assegurando que seja evitado o individualismo, trazendo benefícios e ganhos para a toda sociedade.

Contudo, a principal função desta Lei, somados aos artigos 31, 70 e 74 da Constituição Federal, segundo Cunha e Souza (2017, p. 25),

\begin{abstract}
Destas normas decorre a possibilidade de cada ente ou Poder instituir mecanismos de controle interno que abrangem poderes investigatórios para apuração de ilícito contábil, financeiro, orçamentário, operacional e patrimonial do ente e das entidades da administração direta e indireta, quanto à legalidade, legitimidade, economicidade, aplicação das subvenções e renúncia de receitas.
\end{abstract}

Porém só a lei não será capaz de trazer as mudanças necessárias se não forem adotadas políticas que estimulem a cooperação entre os envolvidos em determinada negociação, bem como se estabeleça relações negociais duradouras e sustentáveis, a fim de trazer o desenvolvimento para uma amplitude de entes, e não, restritivo a poucos. E sobre estas práticas preventivas que tratou no item seguinte.

\section{PRATICAS COMO PREVENÇÃO A CORRUPÇÃO}

A implantação de políticas de prevenção pelas empresas é essencial para que esta tenha maior controle na busca por aumento da sua lucratividade, pois a ética e a transparência são formas de atrair valorização às empresas, e com isso traz confiança ao mercado. Neste sentido a lei foi criada, facilitando e agilizando 


\section{Personalidade Acadêmica Homenageada:}

Florisbal de Souza Del'Olmo (Professor Convidado - UNICURITIBA)

mudanças institucionais a fim de minimizar, e talvez cessar a prática corruptiva no âmbito empresarial e da administração pública.

A Lei em apreço traz em alguns dispositivos sanções que serviriam como forma de coibir os atos de corrupção, uma punição que teria como finalidade o desestímulo de outras empresas cometerem atos ilícitos, sendo o que esta previsto no art. $6^{\circ}$, como comentam Cunha e Souza (2017, p. 64),

[...] a publicação extraordinária da decisão condenatória e ocorrerá na forma de extrato de sentença, a expensas da pessoa jurídica, em meios de comunicação de grande circulação na área da prática da infração e de atuação da pessoa jurídica ou, na sua falta, em publicação de circulação nacional, bem como por meio de afixação de edital, pelo prazo mínimo de 30 (trinta) dias, no próprio estabelecimento ou no local de exercício da atividade, de modo visível ao público, e no sítio eletrônico na rede mundial de computadores.

Porém, há que se ter cuidado quanto à intensidade e majoração da punição vista como exemplo, pois esta pode servir para que o julgador aplique sanção de forma desproporcional e acima do que seria justo, trazendo consequências que poderiam ser financeiramente irreversíveis a sobrevivência da empresa.

As multas a serem aplicadas as empresas infratoras, previstas pela Lei, também seria outra forma eficaz para a prevenção e punição destas, porém esta multa deve ser sentida pela empresa no sentido de se sobrepor aos lucros auferidos pela corrupção servindo desta forma como desestímulo a novas práticas.

Para se alcançar um valor adequado para a multa, é necessário, portanto, conhecer bem a situação financeira da empresa, sendo o faturamento bruto apenas um dos parâmetros. Indicadores de liquidez, estrutura de capital (endividamento), rentabilidade e lucratividade apresentam um panorama geral de toda a situação econômica, patrimonial e financeira de uma empresa e são importantes para a dosimetria da multa. (QUEIROZ, 2015, p. 317).

De acordo com entendimento de José Munhoz de Souza (2015, p. 142) destaca que: 


\title{
Personalidade Acadêmica Homenageada:
}

Florisbal de Souza Del'Olmo (Professor Convidado - UNICURITIBA)

[...] andou mal o legislador ao se referir apenas ao faturamento, sem permitir que a multa incidisse também sobre a receita bruta, o que promete reacender diversas discussões já enfrentadas pelo STF quando da análise de questionamentos sobre a constitucionalidade da equiparação legal dos conceitos de faturamento e receita bruta pela legislação tributária do PIS/COFINS.

Contudo, a prevenção à corrupção decorre de atos conjuntos e da aplicação de diversas leis e regramentos de condutas existentes em nosso ordenamento jurídico vigente, pois segundo preleciona Norberto Bobbio (1999, p. 31),

\begin{abstract}
O ordenamento jurídico (como todo o sistema normativo) é um conjunto de normas. Essa definição geral de ordenamento pressupõe uma única condição: que na constituição de um ordenamento concorram mais normas [...]. Poderíamos imaginar um ordenamento jurídico composto de uma só norma? Penso que a existência de tal ordenamento deva ser excluída. (grifos do autor).
\end{abstract}

Sendo assim, se faz necessário a ação conjunta de diversos órgãos que formam a administração pública e que detém a função fiscalizadora e punitiva, bem como a reunião de todas as leis capaz de fundamentar as punições, para que assim se torne efetivo e concreto tais punições.

Não custa lembrar que, quando os Estados Unidos aprovaram a sua lei anticorrupção em 1977 (FCPA - Foreign Corrupt Practices Act), proibindo que suas empresas subornassem funcionários públicos de governos estrangeiros, a primeira reação das corporações americanas foi de que, se elas não participassem do esquema, fazendo o mesmo jogo, seriam aniquiladas do mercado global, que era tolerante com o suborno transnacional. Ou se mudava uma cultura ou se perpetuava um vício. Foi necessário toda uma articulação internacional das grandes potências econômicas para a aprovação da convenção sobre combate à corrupção de funcionários públicos estrangeiros em transações comerciais internacionais, da OCDE, sobre a qual o Brasil é signatário e que foi a principal fonte de pressão para a aprovação da Lei 12.846/2013. (QUEIROZ, 2016, p. 123).

Outra prática que esta em fase de desenvolvimento, mas já prevista na presente Lei é descrita com a expressão "programa de integridade" e que nada mais é do que Compliance. 


\title{
Personalidade Acadêmica Homenageada:
}

Florisbal de Souza Del'Olmo (Professor Convidado - UNICURITIBA)

\subsection{COMPLIANCE}

Segundo entendimento de Guimarães (2014, p. 100) compliance é o "conjunto de medidas de controle interno que a empresa possa adotar no sentido de evitar desvios de comportamento pelos seus funcionários". Essa expressão deriva do inglês to comply que é traduzida como adequar, cumprir, obedecer.

Esta prática é um mecanismo de controle e acompanhamento das atividades realizadas por entidades do terceiro setor quando firmam contratos com a Administração pública, e consiste em um dever de estar em conformidade com as leis e com as regras e recomendações internas, sendo este uma forma de implantação de um código de conduta e de autorregulação, que exige a previsão de procedimentos para promover a prestação de contas e comportamentos éticos por todos os envolvidos na relação empresarial a qual esta submetida.

De acordo com o artigo 41 do Decreto no 8.420/2015, que regulamenta a Lei 12.846/2013, explica que:

\begin{abstract}
Art. 41. Para fins do disposto neste Decreto, programa de integridade consiste, no âmbito de uma pessoa jurídica, no conjunto de mecanismos e procedimentos internos de integridade, auditoria e incentivo à denúncia de irregularidades e na aplicação efetiva de códigos de ética e de conduta, políticas e diretrizes com objetivo de detectar e sanar desvios, fraudes, irregularidades e atos ilícitos pratiçados contra a administração pública, nacional ou estrangeira. Parágrafo Único. O programa de integridade deve ser estruturado, aplicado e atualizado de acordo com as características e riscos atuais das atividades de cada pessoa jurídica, a qual por sua vez deve garantir o constante aprimoramento e adaptação do referido programa, visando garantir sua efetividade. (BRASIL, 2013, s/p).
\end{abstract}

Porém, o Compliance trazido pela Lei na forma de "programa de integridade" requereria constante e rápido desenvolvimento.

De outro lado, no atual estágio em que se encontram as relações negociais, celebradas com grande velocidade, informalidade e sem conhecimento de fronteiras geopolíticas, exigir que a legislação regulamente programas de integridade detalhadamente levaria ao risco de uma constante desatualização do instituto e consequente desestímulo na sua adoção. (CUNHA; SOUZA, 2017, p. 77). 
Personalidade Acadêmica Homenageada:

Florisbal de Souza Del'Olmo (Professor Convidado - UNICURITIBA)

A Lei Anticorrupção estabelece incentivo para a criação de programas de compliance a fim de reduzir as penalidades que poderão ser aplicadas no caso de haver um processo de responsabilização. Esta prática se tornou um ato necessário não por que a lei estabelece esta atenuação, mas pelo fato de que ao diminuir a probabilidade de desvios, a empresa estará sendo beneficiada economicamente com tal precaução.

Segundo entende Ribeiro e Diniz (2015, p. 100) "a implantação efetiva de uma política de Compliance auxilia na busca e na consolidação da confiança em âmbito nacional e internacional, valor inestimável para uma empresa, porque motiva a reciprocidade e suplanta métricas monetárias, deixando de ser apenas um ônus e revelando-se como a mais perfeita tática competitiva de negócio".

Este tipo de medida tem por finalidade coibir desvios e corrigir possíveis fragilidades da empresa que dificulte a ocorrência de atos capazes de serem passíveis de corrupção, porém há que se ter ciência que não é possível impedir totalmente todas as possibilidades de ilicitude, mas quando as medidas preventivas forem eficientes, trará dificuldades para as ilicitudes se concretizarem.

De acordo com Ronaldo Pinheiro de Queiroz (2016, p. 122)

Se o Brasil quer melhorar a sua imagem no campo da corrupção (já que acaba de cair 7 posições, estando em $76^{\circ}$ colocado no ranking da transparência internacional de 2015), é preciso mudar a cultura das relações econômicas entre particulares e Poder Público, a partir de uma cruzada contra esse jogo sujo da corrupção pelos seus próprios atores. As empresas que investem em eficiência e boa governança, com programas de compliance efetivos, devem ser as primeiras a denunciarem as partidas compradas, por uma questão, inclusive, de sobrevivência. Se não houver uma cultura de intolerância e de denúncia desses esquemas pelos principais atores interessados, a tendência é que esse ciclo continue favorecendo quem menos favorece o próprio mercado e dissipando a empresa que melhor investe no seu time. Entra aqui uma equação de vida ou morte para ambos os perfis de empresas e o Estado deve estar ao lado das empresas éticas, garantindo a sua sobrevivência.

Os principais valores e aplicações do compliance seria com relação ao respeito dos direitos humanos e condições justas para um local de trabalho 


\section{Personalidade Acadêmica Homenageada:}

\section{Florisbal de Souza Del'Olmo (Professor Convidado - UNICURITIBA)}

adequado, contribuição para maior produtividade, à coerência entre a lei e as práticas da empresa, trazer a integridade na relação com agentes públicos e empresas, e com isso proporcionando a integridade comercial.

Mas para que haja uma efetividade e eficácia da aplicação do compliance, é preciso o comprometimento e apoio dos dirigentes da empresa, por este motivo dizse que é um programa top down, ou seja, deve ser adotado de cima para baixo.

Em consonância com o entendimento de Cunha e Souza (2017, p. 81) "a atuação ética e absolutamente legal desse grupo de pessoas serve para inspirar tanto empregados como usuários, colaboradores e clientes da empresa. Ademais essa condição fortalece a imagem da corporação e serve de motivo para investidores [...]".

Vale destacar que os implementadores das diretrizes deste programa precisam de acesso amplo a todas as áreas da empresa para que assim possam analisar os riscos e identificar as relações da empresa com os agentes públicos, para que assim haja uma gestão colaborativa entre ambos, a fim de determinar programas de prevenção à corrupção, precisaria haver um monitoramento contínuo e comprometimento de todos os envolvidos. Embora a lei tenha sua importância, ela nasce com alguns problemas relacionados a alguns dispositivos, sendo assim se faz necessário alguns apontamentos de críticas que estão sendo abordadas, e sobre isso tratou-se no item seguinte.

\section{CRITICAS A LEI}

Esta Lei foi criada a partir de fatos como manifestação popular e com isso o congresso nacional sentindo-se pressionado, foi obrigado a tomar atitude de aprovar a presente Lei, bem como a fim de cumprir compromissos internacionais, com isso a demora pela aprovação é um ponto que desperta críticas. Porém, segundo alguns juristas, tal lei nasce com problemas graves com relação a alguns de seus dispositivos. 
Personalidade Acadêmica Homenageada:

Florisbal de Souza Del'Olmo (Professor Convidado - UNICURITIBA)

É o que apontam Mateus Bertoncini e Daniel Ferreira (2016, p. 451),

De modo inusitado, o ato lesivo contra a administração pública, nacional ou estrangeira, previsto no art. $5^{\circ}$ da Lei 12.846/2013, exige para a sua punição dois processos, um administrativo, para aplicar determinadas sanções; outro judicial, para pespegar bloco diverso de punições previstas na mesma Lei e para os mesmos fatos ilícitos. [...] Corre-se o risco, pelo mesmo fato ilícito, de uma condenação judicial de pessoa jurídica absolvida administrativamente; ou que se tenha a condenação administrativa, com as sanções já cumpridas (multa e publicação da decisão condenatória), e a absolvição judicial por idêntico ato lesivo. [...] Assim, a solução baseada na autonomia das instâncias penal, civil e administrativa não se aplica à Lei 12.846/2013, pois não se está diante de instâncias autônomas de responsabilidade, mas de uma mesma instância, por uma única modalidade de fato ilícito, o da responsabilidade por ato lesivo à administração pública, nacional ou estrangeira, ou seja, a um tipo de responsabilidade sujeito ao mesmo regime jurídico, mas que prevê 2 (dois) processos distintos para apuração - dualidade processual - e eventual punição, abrindo brecha para a inaceitável possibilidade de decisões contraditórias dentro de um mesmo regime jurídico de responsabilidade, violando o constitucional princípio da segurança jurídica.

Com relação aos processos administrativo e judicial há incongruência que traria insegurança jurídica e que fugiria do padrão do sistema jurídico nacional, que poderiam trazer afronta aos princípios constitucionais como a razoabilidade e segurança jurídica.

Outro ponto crítico da Lei seria com relação à autoridade que julgaria as empresas infratoras, pois a lei prevê como sendo de responsabilidade da administração pública esta incumbência de processar e julgar esta ilicitude. Porém é de se estranhar que a mesma entidade que comete o ato ilícito julgará seus próprios atos, isso dá a sensação de mais impunidade.

Além disso, essa competência administrativa parece contrariar a garantia constitucional inscrita no inc. LIII do art. $5^{\circ}$ da Constituição de 1988, que estabelece que "ninguém será processado nem sentenciado senão pela autoridade competente". Parece surreal que as pessoas jurídicas no Brasil tenham essa garantia somente no que se refere a uma parcela da Lei, ou seja, aquela que trata da responsabilização judicial (arts. 18 a 21), nada garantindo quem será a autoridade responsável pelo processo administrativo, cuja competência pode, inclusive, ser delegada. [...] Independentemente da causa, a falha merece retificação para se suprimir o processo administrativo da Lei 12.846/2013, reservando-se ao Poder Judiciário, com exclusividade, o julgamento da ação civil pública por ato 
Personalidade Acadêmica Homenageada:

Florisbal de Souza Del'Olmo (Professor Convidado - UNICURITIBA)

lesivo à administração pública, nacional ou estrangeira, aplicando-se às pessoas jurídicas, na sua inteireza, as garantias constitucionais do devido processo legal (art. 5으, LIV) e do juiz natural (art. 5으. LIII), ausentes no teratológico processo administrativo da Lei 12.846/2013. (BERTONCINI; FERREIRA, 2016, p.464).

De outro norte, a lei não previu a participação do Ministério Público nos acordos de leniência, o que traria melhores resultados se assim o fizesse, pois é este órgão que detém a titularidade das ações penais e civil públicas, e que poderia ter maiores efeitos e resultados tais acordos. Ainda com relação ao acordo de leniência Magalhães (2014, p. 72), entende que a pessoa jurídica que firmar este acordo estará condenando a pessoa física na esfera penal,

\begin{abstract}
Assim sendo, a confissão de ato lesivo contra o poder público, normalmente também tipificado como ilícito penal, pode até trazer vantagens à pessoa jurídica, mas certamente trará consequências gravosas às pessoas físicas. É curioso observar que, quanto mais colaborar o dirigente ou administrador, mais reduzida ficará eventual sanção pecuniária a ser imputada à pessoa jurídica, e mais implicado ficará o delator na esfera criminal (salvo se houver benefício previsto na legislação processual penal).
\end{abstract}

O benefício do acordo não foi estendido às pessoas físicas ligadas a pessoa jurídica, o que poderá ser um motivo para inibir a realização de acordo, e como entende Bertoncini e Ferreira (2016, p. 468) "à toda evidência, o art. 16 , § $2^{\circ}$, da Lei 12.846/201312 necessita ser reformado, de modo a se garantir os benefícios do acordo de leniência às pessoas físicas envolvidas na prática dos atos lesivos previstos no art. 5o, e não somente à pessoa jurídica, para que o mecanismo se torne eficaz no combate da corrupção".

A Lei traz outros pontos controversos que trazem discussões, como a possibilidade de aplicação de sanção a empresas estatais que cometam ato ilícito, isso pelo fato de haver participação de recursos públicos em sua formação, como exemplo a sociedade de economia mista que é composta por recursos públicos e privados, já a empresa pública é formada com recursos públicos. 
Personalidade Acadêmica Homenageada:

Florisbal de Souza Del'Olmo (Professor Convidado - UNICURITIBA)

No entanto, as sanções administrativas e o perdimento do produto do ato ilícito são plenamente aplicáveis. O regime jurídico não pode ser tido como justificativa plausível para deixar tais empresas à margem da órbita da Lei Anticorrupção. E o mesmo vale para as fundações públicas e partidos políticos [...]. Outro argumento que torna imperiosa a aplicação da referida legislação às empresas estatais diz respeito aos eloquentes casos de corrupção recentes. O "Esquema Mensalão", que foi objeto da Ação Penal 470 no Supremo Tribunal Federal, teve a Empresa Brasileira de Correios e Telégrafos e o Banco do Brasil no centro do esquema de corrupção. Mais recentemente, a "Operação Lava Jato" traz a Petrobras como alvo de uma série de irregularidades. Deixar as empresas estatais de fora e permitir que a corrupção ainda se construa em um dos seus polos mais significativos, onde há a vultuosa movimentação do dinheiro público, significa reduzir 0 espectro de incidência da Lei. (PAZÓ; ESCOSSIA, 2015, p. 214).

O que se nota, é uma gama de críticas que fazem sentido no viés de trazer mudanças necessárias à lei com o intuito de impor eficácia e fazer valer sua necessidade concreta, a fim de erradicar a impunibilidade das ilicitudes contra o patrimônio público, bem como trazer à devida punição as empresas que tem como pratica a corrupção.

\section{CONCLUSÃO}

Para Montesquieu (2005, p.124) a "corrupção de cada governo começa quase sempre pela corrupção dos princípios", e entende que,

[...] ninguém se admire se os sufrágios forem comprados pelo dinheiro. Não se pode dar muito ao povo sem que dele se tire mais ainda; porém, se tirar dele, é necessário derrubar o Estado. Quanto mais o povo pensa auferir vantagens de sua liberdade, mais se aproximara o momento em que deverá perdê-la. Formam-se então pequenos tiranos que possuem todos os vícios de um só. Logo aquilo que restar de liberdade tornar-se-á insuportável: um único tirano surgirá, e o povo perderá tudo, até mesmo as vantagens de sua corrupção (MONTESQUIEU, 2005. p. 125).

A existência de leis que fazem o controle da corrupção, desde a ação diretamente no foco da corrupção até a responsabilização dos agentes, não tem sido empecilho para a ação ilícita de agentes públicos e políticos, que por sua vez agem 


\section{Personalidade Acadêmica Homenageada:}

\section{Florisbal de Souza Del'Olmo (Professor Convidado - UNICURITIBA)}

em proveito próprio ou alheio, e que sendo um agente público no exercício de suas atividades funcionais, devem cumprir com lealdade os ditames legais, incluindo os princípios a eles imputados como a moralidade, sendo esse fundamental à legitimidade de seus atos.

Com a aplicação desta lei, bem como a formação de um banco de dados e de jurisprudências, talvez fosse uma forma de inviabilizar a ação corruptiva, pois com a divulgação ampla e irrestrita de empresas que não cumprem as normas, levaria ao consumidor deixar de consumir dessas empresas ou contratar com estas, convertendo esta ação em uma forma repressiva e sancionadora a suas atitudes ilícitas.

O presente artigo teve como objetivo principal, trazer breve reflexão sobre a necessidade a aplicabilidade da Lei Anticorrupção, o que não almejou exaurir o tema, mas trazer uma análise da percepção desta lei. O que se pode observar é que a presente lei veio para que pudesse reverter o quadro de impunidade das empresas que cometem atos ilícitos ligados à corrupção e fosse responsabilizada objetivamente.

Para um melhor entendimento sobre o tema, foi abordado o assunto que trouxe algumas práticas para a prevenção e punição constante na lei, e a forma que a mesma trouxe como alternativa de prevenção à corrupção, sendo nominado como "programa de integridade" o que seria conhecido como Compliance, e que possibilitaria agregar benefícios a empresa ao implantar tal programa.

Fez-se necessário trazer algumas críticas à lei, o que de todo modo tem importante relevância para o mundo jurídico, pois os problemas apontados poderiam causas desvalorização e inaplicabilidade de procedimentos trazidos pela lei, bem como a punições não efetivas aquelas empresas e pessoas que cometem atos de corrupção.

Como bem coloca Amartya Sen (1999, p.71) "Quanto maior a confiança entre as pessoas, melhor 0 ambiente para 0 desenvolvimento das relações econômicas". 
Personalidade Acadêmica Homenageada:

Florisbal de Souza Del'Olmo (Professor Convidado - UNICURITIBA)

Apesar de ela ter nascido já com algumas falhas constantes em seus dispositivos, se faz necessário à aplicação, bem como sua adaptação as constantes mudanças, sejam elas tecnológicas ou econômicas, pois do contrário a sua ausência traria uma insegurança para futuros investidores, sejam eles de origem transnacionais ou nacionais.

\section{REFERENCIAS}

BERTONCINI, Mateus Eduardo Siqueira Nunes; FERREIRA, Daniel. Atividade Empresarial e Cidadania: Críticas à Lei Anticorrupção Brasileira. Revista JurídicaUNICURITIBA. v.3, № 44, Curitiba, 2016. p. 451-472. Disponível em: < http://revista.unicuritiba.edu.br/index.php/RevJur/article/view/1817> Acesso em: 19 nov. 2017.

Ato de Improbidade Administrativa: 15 anos da Lei 8.429/1992. São Paulo: Editora Revista dos Tribunais, 2007.

BOBBIO, Norberto. Teoria do ordenamento jurídico. 10 ed. Brasília: Universidade de Brasília, 1999.

BRASIL. Lei no 12.846 de 1 de agosto de 2013. Dispõe sobre a responsabilização administrativa e civil de pessoas jurídicas pela prática de atos contra a administração pública, nacional ou estrangeira, e dá outras providências. Disponível em:<http://www.planalto.gov.br/ccivil_03/_ato2011-2014/2013/lei/12846.htm>

Acesso em: 19 nov. 2017

CUNHA, Rogério Sanches; SOUZA, Renee. Lei Anticorrupção Empresarial. Salvador: JusPodivm, 2017.

GUIMARÃES, Rodrigo Rognier Chemim. Da responsabilidade Administrativa: Comentários aos atigos 6ㅇ e 7‥ CAMBI, Eduardo; GUARAGNI, Fábio André (Coords.). BERTONCINI, Mateus Eduardo Siqueira (org.). In: Lei anticorrupção: comentários à Lei 12.846/2013. São Paulo: Almedina, 2014, p. 100. -55.

HAGE SOBRINHO, Jorge. Lei 12.846/2013: Lei da Empresa Limpa. Revista dos Tribunais. São Paulo, Ano 103, v. 947, set/2014.

MAGALHÃES, João Marcelo Rego. Pontos relevantes da Lei Anticorrupção Empresarial Brasileira - Lei no 12.846 de 1ำ de agosto de 2013. Revista da Procuradoria Geral do Banco Central. v. 8. n. 1. jun/2014. 
Personalidade Acadêmica Homenageada:

Florisbal de Souza Del'Olmo (Professor Convidado - UNICURITIBA)

MONTESQUIEU, Charles Louis de Secondat. Do Espírito das Leis. São Paulo: Martin Claret, 2005.

MOREIRA NETO, Diogo de Figueiredo; FREITAS, Rafael Verás de. A Juridicidade da Lei Anticorrupção - Reflexões e interpretações prospectivas. Disponível em: $<$ http://www.fsl.adv.br/sites/www.fsl.adv.br/files/a_juridicidade_da_lei_anticorrupcao_ -_inclusao_em_20.02.14.pdf>. Acesso em: 13 nov. 2017.

OSÓRIO, Fábio Medina. Direito Administrativo Sancionador. 5. ed. São Paulo: Revista dos Tribunais, 2015.

PAZÓ, Cristina Grobério; ESCOSSIA, Matheus Henrique dos Santos. A Lei Anticorrupção e Seu Impacto Transformador: Realidade ou llusão? Revista Jurídica - UNICURITIBA. v. 3, n. 40, 2015, Curitiba, p. 214. Disponível em : <http://revista.unicuritiba.edu.br/index.php/RevJur/article/view/1338/901>. Acesso em: 19 nov. 2017.

PESTANA, Marcio. Lei Anticorrupção - Exame Sistematizado da Lei 12.846/2013. São Paulo: Editora Manole, 2016.

PETRELLUZZI, Marco Vinício; RIZEK JUNIOR, Rubens Naman. Lei anticorrupção. São Paulo: Saraiva, 2014.

QUEIROZ, Ronaldo Pinheiro. Lei Anticorrupção tem como desafio trazer jogo limpo para o mercado. Revista de Filosofia do Direito do Estado e da Sociedade. FIDES, Natal. v8, n.1, jan./jun.2016, p. 121. Disponível em :< http://www.revistafides.com/ojs/index.php/br/article/viewFile/529/842> . Acesso em: 14 nov. 2017.

Responsabilização administrativa na Lei anticorrupção. Lei Anticorrupção (organizadores: Jorge Munhos Souza e Ronaldo Pinheiro de Queiroz). Salvador, Editora Juspodivm, 2015.

RIBEIRO, Marcia Carla Perera; DINIZ, Patrícia Dittrich Ferreira. Compliance e a lei anticorrupção nas empresas. Revista de informação legislativa, v. 52, n. 205, p. 87-105, jan./mar. 2015.

SEN, Amartya. Sobre ética e economia. São Paulo: Companhia das Letras, 1999.

SOUZA, Jorge Munhos; QUEIROZ, Ronaldo Pineiro (orgs). Responsabilização administrativa na Lei anticorrupção. In: Lei Anticorrupção. Salvador: Juspodivm, 2015.

ZAFFARONI, Raúl; PIERANGELI, José Henrique. Manual de Direito Penal Brasileiro - Parte Geral. 7. ed. São Paulo: Revista dos Tribunais, 2008. v. 1. 